JOURNAL OF PUBLIC HEALTH INOVATION (JPHI)

KUNINGAN, VOL. 01 NO.02. JUNI 2021

DOI: $10.34305 /$ jphi.v1i2.300
Ciptaan disebarluaskan di bawah

Lisensi Creative

CommonsAtribusi-NonKomersial-

BerbagiSerupa 4.0

\title{
ANALISIS PENGARUH TERAPI SENAM ANTI STROKE SEBAGAI UPAYA NON FARMAKOLOGI MENURUNKAN TEKANAN DARAH PADA LANJUT USIA (LANSIA) DENGAN HIPERTENSI RINGAN
}

Emi Sumarni, Mamlukah, Rossi Suparman, Ahmad Ropii, M Lukman, Jamaludin, Cipto Sudrajat

STIKes Kuningan

emisumarni19@gmail.com

\begin{abstract}
Abstrak
Lanjut usia (Lansia) merupakan proses alamiah dan berkesinambungan secara bertahap yang dimulai dari bayi, masa kanak-kanak, remaja, dewasa dan lansia. Peningkatan usia harapan hidup pada lansia dapat mempengaruhi aspek kehidupan mereka, seperti perubahan psikologis, fisik, biologis, sosial, dan akan semakin banyak timbul penyakit degeneratif karena proses penuaan tersebut. Salah satunya dapat dilihat dari perubahan pada fungsi kardiovaskular, yang mengakibatkan tekanan darah meningkat atau akan menimbulkan hipertensi. Tujuan penelitian ini adalah untuk melihat pengaruh senam anti stroke terhadap penurunan tekanan darah pada lansia dengan hipertensi ringan. Jenis pada penelitian ini adalah eksperimen semu dengan pretest dan posttest only design, dimana akan dilakukan pengukuran tekanan darah sebelum dan sesudah perlakuan senam anti stroke. Sampel pada penelitian ini adalah setiap lansia yang menderita kategori hipertensi ringan yang berjumlah 20. Instrumen penelitian adalah SOP senam anti stroke, tensimeter digital, buku catatan. Analisis data yang digunakan untuk melihat pengaruh senam anti stroke terhadap penurunan tekanan darah pada lansia dengan hipertensi ringan menggunakan analisis statistik uji paired t test dengan derajat kepercayaan $\alpha=0,05$. Berdasarkan hasil analisis univariat menunjukan terdapat penurunan tekanan darah pada lansia sebelum perlakuan dengan mean sistole sebesar 151.70 dan diastole sebesar 87.10, sedangkan pada mean tekanan darah setelah diberikan perlakuan mean sistole sebesar 126 dan diastole sebesar 79.95. berdasarkan hasil uji bivariat menunjukan bahwa terdapat pengaruh senam anti stroke terhadap penurunan tekanan darah pada lansia dengan hipertensi ringan dengan nilai $\mathrm{p}=0,000$. Berdasarkan hasil tersebut simpulan pada penelitian ini adalah terdapat pengaruh senam anti stroke terhadap tekanan darah pada lansia dengan hipertensi ringan.
\end{abstract}


JOURNAL OF PUBLIC HEALTH INOVATION (JPHI)

KUNINGAN, VOL. 01 NO.02. JUNI 2021

DOI: $10.34305 /$ jphi.v1i2.300
Ciptaan disebarluaskan di bawah

Lisensi Creative

CommonsAtribusi-NonKomersial-

BerbagiSerupa 4.0

Kata Kunci : Senam anti stroke, hipertensi, sistole, diastole

\section{Pendahuluan}

Lanjut usia (Lansia) adalah proses alamiah dan berkelanjutan secara bertahap yang dimulai mereka bayi, lalu kanak-kanak kemudian remaja, dewasa dan lansia. Setiap individu akan mengalami perubahan baik secara anatomi, fisiologis, dan biokimia sejak mulai dari sel sampai sistem organ sehingga mempengaruhi keadaan fungsi dan kemampuan tubuh secara keseluruhan (Fatimah, 2010).

Populasi lansia di Indonesia dalam setiap tahunnya selalu bertambah. Pada tahun 2004-2015 usia harapan hidup di Indonesia meningkat dari 68,6 tahun menjadi 70,8 tahun. Sebaran jumlah lansia di Indonesia terbanyak berada di provinsi DIY sebanyak 13,4\% dan yang terendah berada di provinsi Papua sebanyak 2,8\%. (Kemenkes RI, 2016).

Hipertensi merupakan penyakit tidak menular yang menjadi salah satu penyebab utama kematian prematur di dunia. Organisasi kesehatan dunia (World Health Organization / WHO) mengestimasikan saat ini prevalensi hipertensi secara global sebesar 22\% dari total penduduk dunia. Dari sejumlah penderita tersebut, hanya kurang dari seperlima yang melakukan upaya pengendalian terhadap tekanan darah yang dimiliki. Hasil Riskesdas 2018 menunjukkan angka prevalensi hipertensi pada penduduk $>18$ tahun berdasarkan pengukuran secara nasional sebesar $34,11 \%$ (Riskesdas, 2018).

Riset Kesehatan Daerah (RKD) di Kabupaten Brebes pada 2018 angka penyakit hipertensi sebesar $43.73 \%$ dan pada 2019 angka yang sama terjadi di kecamatan Salem. Angka kejadian hipertensi pada 2018 sebesar $32.20 \%$. Di wilayah Puskesmas Bentar sebesar 25.5\% dan di wilayah Puskesmas Salem sebesar 37.31\%. Data ini diperoleh dari hasil sasaran di wilayah Puskesmas Bentar sebesar 8.718 jiwa dan Puskesmas Salem dari hasil sasaran 11.361. Dari hasil pendataan berkelanjutan 2019, diperoleh data yang menderita hipertensi di Puskesmas Bentar sebanyak 2.302 sedangkan di Puskesmas Salem sebanyak 4.234 kasus. Dari sebaran usia penderita hipertensi untuk Desa di wilayah Puskesmas Bentar jumlah penderita hipertensi berada pada rentang usia $>15-60$ tahun. Desa tersebut terdiri dari: Wanoja 214 kasus, Pabuaran 43 kasus, pasir panjang 50 kasus, Bentar 195 kasus, Bantarsari 40 kasus, Ciputih 52 kasus, Gandoang 76 kasus, Kadu 
JOURNAL OF PUBLIC HEALTH INOVATION (JPHI)

KUNINGAN, VOL. 01 NO.02. JUNI 2021

DOI: $10.34305 /$ jphi.v1i2.300
Ciptaan disebarluaskan di bawah

Lisensi Creative

CommonsAtribusi-NonKomersialBerbagiSerupa 4.0
Manis 81 kasus. Dari 8 Desa tersebut angka tertinggi adalah Desa Wanoja. (Dinas Kesehatan Kabupaten Brebes, 2019).

Upaya pengobatan hipertensi nonfarmakologis dengan cara memberi terapi dalam bentuk olahraga yang adekuat untuk lansia. Jenis olahraga yang dapat dipilih lansia sebagai aktivitas fisik adalah senam. Melakukan senam secara teratur berguna untuk memperlambat atau mencegah penurunan fungsi sistem tubuh. Beberapa penelitian menunjukkan bahwa senam pada lansia dapat mengurangi berbagai macam risiko hipertensi. Senam secara teratur akan menurunkan tekanan darah, karena mampu menstimulasi kerja saraf perifer khususnya saraf parasimpatis yang bisa menyebabkan vasodilatasi pembuluh darah sehingga terjadi penurunan darah sistol dan diastol (Moniaga, 2013).

Pada tahun 2025 mendatang, diperkirakan kurang lebih 29\% warga dunia menderita hipertensi. Saat ini persentase penderita hipertensi didominasi oleh negara berkembang. Data WHO 2015 menunjukkan sekitar 1,13 Miliar orang di dunia menyandang hipertensi, artinya 1 dari 3 orang di dunia terdiagnosis hipertensi. Jumlah penyandang hipertensi terus meningkat setiap tahunnya, diperkirakan pada tahun 2025 akan ada 1,5 miliar orang yang terkena hipertensi, dan diperkirakan setiap tahunnya 10,44 juta orang meninggal akibat hipertensi dan komplikasinya (WHO, 2015).

Peningkatan usia harapan hidup pada lansia dapat mempengaruhi aspek kehidupan mereka, seperti perubahan psikologis, fisik, biologis, sosial, dan akan semakin banyak timbul penyakit degeneratif karena proses penuaan tersebut. Salah satunya dapat dilihat dari perubahan pada fungsi kardiovaskular, yang mengakibatkan tekanan darah meningkat atau akan menimbulkan hipertensi pada lansia (Maryam, 2011). Banyak masyarakat berasumsi bahwa ada keluhan dan tandatanda yang menunjukkan seseorang terkena hipertensi, padahal tidak demikian. Hipertensi tidak menunjukkan keluhan dan tanda yang khusus, karena itulah hipertensi biasanya disebut sebagai silent killer. Bahkan beberapa fakta membuktikan bahwa satu dari empat penderita hipertensi tidak menyadari bahwa mereka menderita hipertensi (Dewi dan Familia, 2010).

Salah satu faktor yang menyebabkan terjadinya hipertensi adalah kurangnya aktivitas fisik (Sudoyo, 2009). Kurang aktivitas fisik meningkatkan risiko seseorang terserang penyakit hipertensi. Orang yang tidak aktif cenderung memiliki 
JOURNAL OF PUBLIC HEALTH INOVATION (JPHI)

KUNINGAN, VOL. 01 NO.02. JUNI 2021

DOI: $10.34305 /$ jphi.v1i2.300
Ciptaan disebarluaskan di bawah

Lisensi Creative

CommonsAtribusi-NonKomersialBerbagiSerupa 4.0 frekuensi denyut jantung lebih tinggi sehingga otot jantung harus bekerja lebih keras pada saat kontraksi (Yulianti \& Sitanggang, 2006). Seseorang yang tidak aktif secara fisik memiliki resiko 30-50\% lebih besar untuk mengalami hipertensi (Price, 2005).

Salah satu aktivitas fisik senam yang dapat dilakukan pada lansia yang alami hipertensi ringan adalah senam anti stroke. Latihan ini dilakukan 1 sampai 2 kali dalam seminggu selama 20-30 menit, dengan periode pemanasan dan pendinginan. Senam anti stroke merupakan olahraga yang ringan dan mudah dilakukan, memiliki gerakan yang dinamis, memberikan perasaan senang dan semangat serta beban yang sedikit. Aktifitas ini membantu tubuh menjaga kebugaran dan tetap segar karena mampu melatih tulang menjadi kuat, mendorong kerja jantung agar optimal dan membantu menghilangkan radikal bebas didalam tubuh. Aktivitas ini dapat membentuk dan membesarkan sikap dan gerak serta memperlambat proses degenerasi karena proses penuaan, juga mempermudah dalam penyesuaian kesehatan jasmani khususnya kesehatan kardiovaskuler dalam adaptasi kehidupan lansia (Nugroho, 2008).

Senam anti stroke adalah salah satu senam yang bermanfaat untuk membantu mengurangi resiko terjadinya stroke pada seseorang yang menderita penyakit diabetes dan hipertensi. Tujuan senam anti stroke untuk memperlancar proses degenerasi karena perubahan usia mempermudah untuk menyesuaikan kesehatan jasmani dalam kehidupan adaptasi, fungsi melindungi, yaitu memperbaiki tenaga cadangan dalam fungsinya terhadap bertambahnya tuntunan, misalnya sakit. Sebagai rehabilitas pada lanjut usia terjadi penurunan massa otot serta kekuatannya, laju denyut jantung maksimal, toleransi latihan, kapasitas aerobic dan terjadinya peningkatan lemak tubuh (Irfan, 2010)

Tujuan penelitian ini adalah untuk melihat pengaruh senam anti stroke terhadap penurunan tekanan darah pada lansia dengan hipertensi ringan.

\section{Bahan Dan Metode}

Penelitian ini adalah jenis penelitian eksperimen dengan pre-test dan post-test only design yaitu melihat pengaruh senam anti terhadap penurunan tekanan darah sebelum dan setelah diberikan perlakuan. Subjek penelitian ini adalah lansia dengan kategori usia 45-59 tahun dan menderita hipertensi ringan, sedangkan dalam pengambilan sampel menggunakan teknik purposive sampling karena pengambilan 
JOURNAL OF PUBLIC HEALTH INOVATION (JPHI)

KUNINGAN, VOL. 01 NO.02. JUNI 2021

DOI: $10.34305 /$ jphi.v1i2.300
Ciptaan disebarluaskan di bawah sampel pada kelompok lansia dengan jumlah 20 yang masuk dalam kriteria responden. Dalam penelitian ini menggunakan instrumen yaitu: buku catatan pengukuran tekanan darah sebelum dan sesudah diberikan perlakuan senam anti stroke.

Pengambilan data penelitian ini dilakukan pada 1 Februari sampai dengan 1 april 2021 yang bertempat di Posbindu Lansia Desa Wanoja Kecamatan Salem Kabupaten Brebes Jawa Tengah. Pengambilan data dilakukan dengan cara mengukur tekanan darah responden sebelum dan sesudah dilakukan perlakuan senam anti stroke Analisa data yang dilakukan meliputi analisis univariat dan bivariat menggunakan uji korelasi paired t-test, dengan tingkat kepercayaan $\alpha=0,05$.

\section{Hasil}

Analisis univariat digunakan untuk mengetahui rata-rata perbedaan pengukuran tekanan darah sebelum dan sesudah perlakuan senam anti stroke.

\section{Tabel 1. Hasil Analisis Univariat}

\begin{tabular}{cccc}
\hline Variabel & Jumlah Responden & $\begin{array}{c}\text { Mean Sebelum Perlakuan } \\
(\mathbf{m m H g})\end{array}$ & $\begin{array}{c}\text { Mean } \\
\text { Setelah Perlakuan } \\
(\mathbf{m m H g})\end{array}$ \\
$\begin{array}{c}\text { Tekanan Darah } \\
\text { Sistolik }\end{array}$ & 20 & 151.70 & 126 \\
$\begin{array}{c}\text { Tekanan Darah } \\
\text { Diastolik }\end{array}$ & 20 & 87.10 & 79.95 \\
\hline
\end{tabular}

Berdasarkan Tabel 1 menunjukkan mean tekanan darah sebelum diberikan perlakuan senam anti stroke pada responden dengan sistole sebesar 151.70 dan diastole sebesar 87.10. sedangkan pada mean tekanan darah setelah diberikan perlakuan senam anti stroke pada responden dengan sistole sebesar 126 dan diastole sebesar 79.95 .

\section{Tabel 2. Hasil Uji Paired t-test}

\begin{tabular}{cccccc}
\hline Variabel & \multicolumn{2}{c}{ Sebelum perlakuan } & \multicolumn{2}{c}{ Setelah perlakuan } & \multicolumn{2}{c}{$p$-value } \\
& Mean & SD & Mean & SD & \\
Sistolik & 151.7 & 4.911 & 126 & 4.437 & 0,000 \\
Diastolik & 87.1 & 5.990 & 79.95 & 4.224 & 0,000 \\
\hline
\end{tabular}


JOURNAL OF PUBLIC HEALTH INOVATION (JPHI)

KUNINGAN, VOL. 01 NO.02. JUNI 2021

DOI: $10.34305 /$ jphi.v1i2.300
Ciptaan disebarluaskan di bawah

Lisensi Creative

CommonsAtribusi-NonKomersial-

BerbagiSerupa 4.0
Berdasarkan Tabel 5.1 menunjukkan bahwa dari hasil uji statistik $\mathrm{t}$ dependent diperoleh $p$ value sistole $=0,000$ dan $p$ value diastole $=0.000$ dimana keduanya lebih kecil dari nilai alpha $(p<0.05)$, berarti ada pengaruh antara tekanan darah sistole dan diastole sebelum dan sesudah perlakuan senam anti stroke pada responden.

\section{Pembahasan}

Hasil Univariat

Penelitian ini melibatkan 20 responden yang diberikan senam anti stroke sebanyak 16 kali dalam waktu 2 bulan. Dimana responden penelitian ini dilakukan pengukuran tekanan darah dengan tensimeter digital. Diketahui berdasarkan hasil penelitian menunjukan mean tekanan darah sebelum diberikan perlakuan senam anti stroke pada responden dengan sistole sebesar 151.70 dan diastole sebesar 87.10. sedangkan pada mean tekanan darah setelah diberikan perlakuan senam anti stroke pada responden dengan sistole sebesar 126 dan diastole sebesar 79.95.

Senam ini dapat menurunkan tekanan darah sistolik melalui berbagai cara yaitu peningkatan pelepasan Nitric Oxide (NO), penurunan kekakuan arteri, dan peningkatan sensitivitas baroreseptor serta penurunan aktivitas simpatis. Senam anti stroke peningkatan aktivitas parasimpatis. Saraf parasimpatis ini kemudian akan mensekresi neurotransmitter asetilkolin (Ach) yang menyebabkan peningkatan pelepasan NO endotel. Peningkatan pelepasan NO endotel ini yang menyebabkan penurunan kekakuan arteri. NO yang disebut juga dengan Endothelium Derived Relaxing Factor (EDRF), dapat menyebabkan terjadinya relaksasi otot jantung dan pembuluh darah (Sherwood, 2011).

Aktivitas fisik meningkatkan kekuatan dan frekuensi tekanan berulang pada endotel, sehingga dapat melepaskan beberapa faktor endotel yang dapat meningkatkan sensitivitas baroreseptor (Yusuf et al., 2005). Sistem baroreseptor bekerja dengan menghambat keluaran simpatis yang menyebabkan aktivitas simpatis menurun sehingga menyebabkan terjadinya penurunan tekanan darah dengan cara menurunkan tahanan perifer yang dapat menurunkan tekanan pengisian jantung sehingga tonus parasimpatis ke jantung meningkat yang menyebabkan terjadinya perlambatan denyut jantung dan berkurangnya kontraktilitas dan akhirnya akan menghambat sekresi ADH.

Selain itu penurunan aktivitas simpatis akan mengurangi produksi renin 
JOURNAL OF PUBLIC HEALTH INOVATION (JPHI)

KUNINGAN, VOL. 01 NO.02. JUNI 2021

DOI: $10.34305 /$ jphi.v1i2.300
Ciptaan disebarluaskan di bawah

Lisensi Creative

CommonsAtribusi-NonKomersialBerbagiSerupa 4.0 dan angiotensin II, sehingga dapat menurunkan reabsorbsi air, reabsorbsi garam, vasokonstriksi dan kontraktilitas jantung (Fidyastria, 2017).

\section{Hasil Bivariat}

Berdasarkan hasil analisis pada penelitian ini menunjukkan bahwa dari hasil uji statistik $\mathrm{t}$ dependent diperoleh $p$ value sistole $=0,000$ dan $p$ value diastole $=0.000$ dimana keduanya lebih kecil dari nilai alpha $(p<0.05)$, yang berarti terdapat perbedaan antara tekanan darah sistole dan diastole sebelum dan sesudah perlakuan senam anti stroke pada lansia di Desa Wanoja Kecamatan Salem Kabupaten Brebes.

Penelitian ini sejalan dengan penelitian ( Dewi, 2010) yang menunjukan hasil uji statistik didapatkan $p$ value sistol $=$ 0.014 dan $p$ value diastol $=0.000$ dimana keduanya lebih kecil dari nilai alpha $(\mathrm{p}<"$ (0.05), berarti Ho ditolak. Hal ini menunjukkan bahwa adanya perbedaan yang signifikan rata-rata tekanan darah baik sistole maupun diastole sesudah diberikan terapi kombinasi kukusan labu siam dan senam anti stroke antara kelompok intervensi dan kelompok kontrol yang tidak diberikan terapi.

Peneliti melihat adanya perbedaan antara sebelum dan setelah perlakuan senam anti stroke dipengaruhi oleh sebagian besar rata-rata responden dari mulai perlakuan pertama sampai akhir mengikuti SAS dengan benar dan sesuai gerakanya, berdasarkan hasil penelitian rata-rata 14 (70\%) responden mengikuti senam anti stroke dengan benar.

Penelitian ini juga sejalan dengan penelitian Melati (2021) yang menyatakan bahwa aktivitas fisik dengan intensitas sedang seperti senam berpengaruh dalam menurunkan tekanan darah. Pernyataan ini sejalan juga dengan yang disampaikan Aji (2015) yang menyampaikan orang yang melakukan latihan fisik dapat menurunkan terjadinya penyakit hipertensi karena bisa membakar lemak yang mampu membuat penyumbatan pada dinding pembuluh darah, sehingga arteri koronaria atau pembuluh darah jantung akan lebih lebar dibandingkan dengan orang yang tidak melakukan latihan fisik.

\section{Kesimpulan}

Berdasarkan hasil analisis univariat menunjukan terdapat penurunan tekanan darah pada lansia sebelum perlakuan dengan mean sistole sebesar 151.70 dan diastole sebesar 87.10, sedangkan pada mean tekanan darah setelah 
JOURNAL OF PUBLIC HEALTH INOVATION (JPHI)

KUNINGAN, VOL. 01 NO.02. JUNI 2021

DOI: $10.34305 /$ jphi.v1i2.300
Ciptaan disebarluaskan di bawah

Lisensi Creative

CommonsAtribusi-NonKomersial-

BerbagiSerupa 4.0

Aji. (2015). Pengaruh senam Aerobik Terhadap Penurunan Tekanan Darah Di Posyandu Gunung Kidul Yogyakarta. Universitas 'Aisyah Yogyakarta.

menunjukan bahwa terdapat pengaruh senam anti stroke terhadap penurunan tekanan darah pada lansia dengan hipertensi ringan dengan nilai $\mathrm{p}=0,000$. Berdasarkan hasil tersebut simpulan pada penelitian ini adalah terdapat pengaruh senam anti stroke terhadap tekanan darah pada lansia dengan hipertensi ringan.

\section{Saran}

Bagi Lansia untuk menjaga kebugaran dan menurunkan hipertensi dengan tetap konsisten menjalankan senam anti stroke walaupun dilakukan sendiri. Bagi Posbindu Lansia Desa Wanoja agar senam anti stroke menjadi program rutin bagi lansia di posbindu lansia Desa Wanoja sehingga para lansia menjadi lebih produktif.

\section{Bagi UPTD Puskesmas Bentar}

Sebagai pemegang program di Posbindu Lansia harus menjaga program SAS ini terus dilakukan menjadi program rutin Puskesmas dan sekaligus intervensi penanggulangan hipertensi di wilayah kerja UPTD Puskesmas Bentar.

\section{Daftar Pustaka}

Dewi, S. dan F. (2010). Hidup Bahagia Bersama Hipertensi. A Plus Book.

Dinas Kesehatan Kabupaten Brebes. (2019). Prevalensi Hipertensi di Kabupaten Brebes.

Fatimah. (2010). Merawat Manusia Lanjut Usia. Trans Info Media.

Fidyastria, K. (2017). Pengaruh senam anti stroke terhadap penurunan tekanan darah pada lansia dengan hipertensi di UPTD Griya Wreda Surabaya. Universitas Airlangga.

Irfan, M. (2010). Fisioterapi Bagi Insan Stroke. Graha Ilmu.

Kementerian Kesehatan Republik Indonesia. (2016). Populasi Lanjut Usia.

Maryam, R. S. dkk. (2011). Mengenal Usia Lanjut dan perawatannya. Salemba Medika.

Moniaga, V. (2013). Pengaruh Senam Bugar Lansia Terhadap Tekanan Darah Penderita Hipertensi Di Bplu Senja Cerah Paniki Bawah. Jurnal EBiomedik, 1 (2), 785=789.

Nugroho. (2008). Keperawatan gerontik dan geriatrik edisi 3. EGC.

Riset Kesehatan Dasar. (2018). Prevalensi angka hipertensi di Indonesia.

S., P. (2005). Patofisiologi Konsep Klinis Proses-Proses Penyakit. 
JOURNAL OF PUBLIC HEALTH INOVATION (JPHI)

KUNINGAN, VOL. 01 NO.02. JUNI 2021

DOI: $10.34305 /$ iphi.v1i2.300

Sudoyo. (2009). Buku Ajar Ilmu Penyakit Dalam, jilid II, edisi $V$. Interna Publishing.

World Health Organization. (2015). Data Hipertensi perkiraan 2025.

Yulianti, S., \& Sitanggang, M. (2006). Menuju hidup sehat: 30 ramuan penakluk hipertensi. Agromedia Pustaka.

Yusuf. (2005). Hubungan Aktivitas Fisik Dengan Derajat Hipertensi Pada Lansia. Jurnal Berkala Kesehatan, 1(12), 112-117. 